\title{
Ecological citizenship: a driver of pro-environmental behaviour?
}

\author{
Sverker C. Jagers ${ }^{1}$, Johan Martinsson ${ }^{2}$, Simon Matti ${ }^{3}$
}

\begin{abstract}
From a mainly theoretical point of departure, an Ecological Citizenship has been suggested to function as a driver for the individual's pro-environmental behaviour (PEB), providing a more stable foundation for lifestyle changes than, for instance, economic or other external policy tools. In this paper, we take our starting-point in the notion of ecological citizenship (EC) as outlined by, among others, Dobson (2007). Our objective is to examine the relevance of Ecological Citizenship ideals for explaining pro-environmental behavior, by applying unique survey data from a mail questionnaire sent out to a random sample of the Swedish population in 2009, specifically designed to capture various aspects of EC. We find that there are people fulfilling the demands expressed by EC-theory, that - compared to average people - individuals who think along the lines of ecological citizenship are more likely to behave in an environmentally friendly way in their ordinary lives, and that certain aspects of EC are more important for pro-environmental behavior than others.
\end{abstract}

Keywords: Sustainable development, ecological citizenship, environmental concern, proenvironmental behaviour

\section{Paper to be presented at SWEPSA (Swedish Political Science Association),} Umeå 27-28/10 2011.

\footnotetext{
${ }^{1}$ Luleå University of Technology \& University of Gothenburg. Sverker.jagers@pol.gu.se

${ }^{2}$ University of Gothenburg. Johan.martinsson@pol.gu.se

${ }^{3}$ Luleå University of Technology. Simon.matti@ltu.se
} 


\section{Introduction}

From a mainly theoretical point of departure, an ecological citizenship has been suggested to function as a driver for the individual's pro-environmental behaviour (PEB), providing a more stable foundation for lifestyle changes than, for instance, economic or other external policy tools. In this paper, we take our starting-point in the notion of ecological citizenship (EC) as outlined by, among others, Dobson (2007). Our objective is to examine the relevance of theoretically derived ecological citizenship ideals for explaining pro-environmental behavior, by applying unique survey data from a mail questionnaire sent out to a random sample of the Swedish population in 2009 , specifically designed to capture presence and strength of the various aspects of $\mathrm{EC}$ with individuals.

The current literature on environmental politics and policy is increasingly recognising that environmental problems have their sources also in the aggregated consequences of citizen's unsustainable ways of life (e.g. Hobson, 2004). Following this change in perspectives, it is furthermore argued that properly amending such problems requires that individual citizens incorporate ecological considerations in their day-to-day choices and activities. In parallel, however, calling for a more comprehensive individual involvement in the environmental work also means that policy-makers face the significant task of designing policies and policy instruments that effectively address the citizen's engagements, while at the same time remaining within the framework of what is considered a legitimate exercise of political authority among the general public (Jagers \& Hammar 2009; Matti, 2009).

To date, this institutional dilemma has predominately been addressed via a focus on incentive-based behavioural changes. Through the use of economic (dis)incentives, citizens are encouraged to voluntarily change their behaviour in a number of well-defined householdrelated activities; for example patterns of consumption.. This approach of changing incitementstructures from the top and down has been demonstrated as being rather effective when it comes to governing specific changes in behaviour in a short-term perspective (Sterner, 2003); and transformed patters of households' day-to-day activities are indeed critical elements for reaching the objective of ecological sustainability (Conca et al., 2001; but see Seyfang, 
Paper to be presented at SWEPSA (Swedish Political Science Association), Umeå 27-28/10 2011.

2005:296-298). Yet, for a number of reasons, the ability of a purely incentive-based approach to reform patterns of social choice towards ecological sustainability has been questioned. Its critics argue that minor adjustments of market mechanisms and individual responses disregard and even reduce public motivations for other forms of individual environmental initiatives, as people are encouraged to respond to the (fiscal) incentive itself rather than to the (moral) reasons behind it (Barry, 1999; Berglund and Matti, 2006; Dobson 2007; Hobson, 2002; Jacobs, 1999; Maniates, 2001). Furthermore, by focusing solely on integrating ethical and environmental concerns within the framework of the individual's market-behaviour, it refrains from profoundly challenging the values, beliefs and attitudes underpinning individuals' established lifestyles, thus offering an "easy symbolic alternative to confronting the structural causes of ecological destruction" (Dryzek, 2005:132; also Cohen, 2005; Seyfang, 2005).

Alternative discourses of individual environmental action have therefore been suggested by political theorists, more readily adapting individual rights and responsibilities to incorporate also global and future environmental consequences of private activities. Centre stage, an ecological citizenship ${ }^{4}$, based on the ideals of social justice non-contractual private relations and a non-territorial, as well as asymmetrical, scope of responsibilities aims at engaging citizens in a more comprehensive and values-driven rethinking of their daily habits, rather than mechanically changing behaviours in response to external motivations (read monetary or legal policy instruments).

Although the past years have seen an increasing amount of work developing the notion of an ecological take on citizenship and the responsibilities and obligations for individuals this implies, they have largely remained theoretical and only a few have attempted to address the EC - PEB connection empirically (Carter \& Huby, 2006; Horton, 2005; Seyfang, 2006; Wolf, 2007). Yet fewer apply comprehensive, quantitative data for scrutinizing the existence of values-based ecological citizenship ideals among the general public (e.g. Berglund \& Matti, 2006; Jagers, 2009; Jagers \& Matti, 2010), and systematically explore the strength by which these ideals contribute to individuals' pro-environmental behaviour. This lack of thorough

\footnotetext{
${ }^{4}$ Other concepts have also been used in this regard, for example environmental citizenship (Dobson, 2003);
} ecological stewardship (Barry, 1999); or sustainability- or green citizenship (Bell, 2005:180-181 \& 193n2). 
Paper to be presented at SWEPSA (Swedish Political Science Association), Umeå 27-28/10 2011.

empirical studies is certainly a shortcoming within the EC-literature that needs to be addressed. It is also somewhat surprising as a range of other studies, primarily within political and environmental psychology, validates a central underpinning assumption within EC-theory; that the nature of personally held system of values and beliefs constitutes key factors behind the individual's acceptance of and behavioural response to socio-political phenomena, both in a general political context (e.g. Converse, 1964; Rokeach, 1973; Feldman, 1988; Zaller, 1992) as well as in the specificities of the environmental domain (e.g. Nordlund \& Garvill, 2002; Steg et al, 2005; Stern, 2000; Stern et al, 1995). However, these studies neither aspires to nor do they make efforts to operationalize and test the manner in which the specific ideals put forth by ECtheory affects PEB.

To further our empirical knowledge about ecological citizenship as a driver of PEB, and thus of its very usefulness as a model for broad public environmental engagement ${ }^{5}$, we need to operationalize its ideals in ways that allow for us to measure their existence and strength among the general public, as well as empirically scrutinise the connection between these ideals and PEB. The overarching aim of this article is, therefore, to apply quantitative data analysis in order to examine the relevance of ecological citizenship ideals for explaining pro-environmental behaviour. To fulfill this endeavor, we ask the following questions:

Q1: To what extent do ecological citizens, holding EC-ideals, exist among the general public?

Q2: Do ecological citizenship ideals, as proposed by EC-theory, contribute to proenvironmental behaviour?

Q3: Which aspects of ecological citizenship theory are most important as drivers for proenvironmental behaviour?

In what follows, we first introduce the theory of ecological citizenship more thoroughly and account for how we make it operational. In the next, we present our data and methodological

\footnotetext{
${ }^{5}$ From a policy centred perspective, knowledge of how the values and beliefs implied by the theory of ecological citizenship resonances with mass belief-systems might further be perceived as a requirement for balancing policy effectiveness with legitimacy when promoting a transition to more comprehensive environmental responsibilities for the individual.
} 
Paper to be presented at SWEPSA (Swedish Political Science Association), Umeå 27-28/10 2011.

considerations. Thereafter, the main objective of the article is addressed: what is the relevance of EC for explaining environmentally friendly behavior in practice?

\section{Ecological citizenship: From theory to operationalized concept}

The perceived need to fundamentally rethink the individual's relationship with the environment has been granted attention through a wide range of research, mainly with a strong theoretical focus (e.g. Dobson and Eckersley, 2006; Hailwood 2004; Lundmark 2003; Barry and Wissenburg 2001; Doherty and De Geus 1996; Eckersley 1996, 1995 \& 1992; Dobson, 1995; Achterberg 1993; Saward 1993; Goodin, 1992; Sagoff 1988). In particular, the link between citizenship and the environment as proposed by the theory of ecological citizenship stands in stark contrast to the framing of individual environmental action as purely incentivesdriven, market-based behavioural change. Instead, EC-theory suggests an individual environmental responsibility that is based in interpersonal political relationships; broader in scope, aiming towards the fundamental reshaping of social-environmental relations and targeting lifestyles rather than single activities; and motivates behavioural change by moral considerations rather than by external incentives such as policy instruments (van Steenbergen, 1994; Dobson, 2003 \& 2007; Dobson \& Valencia, 2005). Particular scholarly attention has been paid the ambitious elaboration of EC made by Dobson (2003 \& 2007), in which a more or less complete theory of EC is fleshed out in the shape of fundamental normative and values-based components assumed to generate solid and long-lasting pro-environmental behaviour ${ }^{6}$, and in our attempts to make EC operational, Dobson's accounts therefore receive a somewhat dominating role. When reviewing the literature on EC, we distinguish four characteristic ideals relating to personal environmental obligations.

\section{Social Justice}

At the core of EC-theory we find the primacy of social justice/sense of fairness. In contrast to the remits of traditional political citizenship, some of the EC proponents typically use the

\footnotetext{
${ }^{6}$ A short-version of this theory has been defended and discussed in this journal (see Dobson 2007).
} 
Paper to be presented at SWEPSA (Swedish Political Science Association), Umeå 27-28/10 2011.

metaphor of the ecological footprint (e.g. Wackernagel and Rees, 1996) as a starting-point from which the balance of civic rights and duties emanates. The ecological footprint, and in particular the acknowledgement that individuals in certain parts of the world let their activities expand way beyond what would be possible had the resources been evenly distributed, underpins ecological citizenship's holding of social justice as its core value or virtue (Dobson and Valencia, 2005). In other words, individuals are not asked to change their PEB with the motivation that they will gain personally from doing so. Rather, the duties of ecological citizenship are described as responsibilities for all personal actions that "always already" affect others (cf. Dobson, 2003:49 \& 115). Since all forms of behaviour have an impact on other individuals, the civic duties therefore lies in making these impacts as sustainable as possible and not to use an unequal amount of environmental services, capital or space compared to others. The main (or only) motivation for taking on environmental obligations is, thereby, within an ecological citizenship founded in a sense of social justice; an acknowledgement that it is not right to compromise others ability to lead a full life by upholding an unequal distribution of resources (Connelly and Smith, 2003).

Although a change in behaviour driven by external incentives may very well be interpreted as an important tool for individuals aspiring to reduce their ecological footprint and thereby practise EC (Micheletti, 2003; Seyfang, 2005), this does not by necessity turn them into ecological citizens, neither judging by the full range of their actions nor by the values or motivations underpinning them. Only when a PEB is guided by an intrinsic moral motivation, rather than a financial incentive, it should be considered an act of ecological citizenship. Thus, it is not just a matter of doing green things; it is a matter of being green in doing them too (Dryzek 2005). Following this, in contrast to changes in market-behaviour, the crucial idea behind the notion of an ecological citizenship is the need for a comprehensive rethinking of those values and beliefs dominating the contemporary notion of the proper state/individual as well as human beings/nature relationships (Bell, 2005:182). EC therefore also implies a political responsibility for citizens to promote structural changes; for instance through active participation in deliberations on the values that ought to guide both society in general and policy-making especially (Achterberg, 1993; Barry, 1999).

Building on this theoretical conceptualisation, the social justice aspect of ecological citizenship is broken down into three components to be found and measured in the survey 
Paper to be presented at SWEPSA (Swedish Political Science Association), Umeå 27-28/10 2011.

data: (i) a general sense of fairness; (ii) an awareness of ecological footprints; and (iii) otherregarding motives for pro-environmental behaviour.

\section{Dismantling the distinction between public and private}

A second central aspect of EC-theory is the claim that the distinction between the public and the private sphere should be dismantled. Inspired by feministic political theory (e.g. Prokhovnik, 1998), EC incorporates activities traditionally being regarded as the 'private sphere' and excluded from the public sphere (Dobson, 2003). This is first and foremost due to the shift from framing citizenship as being a political state/individual relationship, to incorporate the noncontractual relations between the citizens themselves on account of the claim that also private relations and acts have an (environmentally degrading) effect in the public arena and thus give rise to citizenship obligations. This feature also indicates a shift in focus from the motivational domains constituting the main demarcation line in the state/individual relations of traditional citizenship theory (e.g. individualism vs. collectivism), and towards values in the range between other-regarding values, and values promoting more of a self-regarding behaviour.

Our attempt at measuring this aspect of ecological citizenship mainly relies on five items where the respondents were allowed to express their view on whether (i) politicians and public authorities should interfere with the behaviour of ordinary people or not, and whether (ii) certain behaviours should be regarded as a private matter or not.

\section{Unbounded responsibilities}

Following the logic inherent in the concept of the ecological footprint, EC is also concerned with obligations that can be captured as unbounded responsibilities. The centrality of interpersonal relations indicates that duties, rather than rights, are core principles for the ecological citizen. EC, furthermore, expands the territorial scope of these civic duties. From being confined within a nation-state, citizenship is now thought of as being global or universal in character (e.g. Jelin, 2000; Christoff, 1996). The space of ecological citizenship is synonymous with the spread of negative effects that our actions have for others, i.e. the scope of citizen duties can be extended both across generations and territorial borders. Pollution does not stop 
Paper to be presented at SWEPSA (Swedish Political Science Association), Umeå 27-28/10 2011.

at national boundaries and, consequently, neither should the duties of the ecological citizen (Dobson, 2003). When making it operational, we attempt to capture the extension of responsibilities to do justice both in time and space, and accordingly divide the aspect of unbounded responsibility into three components: (i) a temporal extension of justice; (ii) a spatial extension of justice; and (iii) a large scope of obligations.

\section{Non-reciprocal responsibilities}

Consistently with the morality of social justice, EC (especially as elaborated by Dobson 2003; 2007) is concerned with the somewhat unconventional normative ideal of non-reciprocal responsibility. This suggests that the duties of the ecological citizen are non-reciprocal in character. Individuals should thus not be asked to take on new duties with the motivation that they will personally gain from them and be able to claim some right or benefit in return. Rather, the duties of ecological citizenship are described as responsibilities for all personal actions that 'always already' affect others (Dobson, 2003:49). The civic duties therefore lie in making these impacts as sustainable as possible and not make use of an unequal amount of environmental goods, services, and space, compared to others. As implied earlier, within an ecological citizenship the main (or only) motivation for taking on environmental obligations is founded in a sense of social justice; an acknowledgement that it is not right to compromise others ability to lead a full life by upholding an unequal distribution of resources (Connelly and Smith, 2003). This also means that acts of balancing may be needed in order to correct an unequal distribution of ecological space, that is to say that some individuals may have to lower their negative environmental contributions while others may have the right to increase their negative environmental impact up to a certain level.

We suggest that this logic is probably best measured via an applied example. Thus, in order to measure the aspect of non-reciprocal responsibilities we designed questions focusing $\mathrm{CO}^{2}$ emissions, as being a highly debated and relevant topic also when it comes to individual-level environmental responsibility. The questions concern people's views both on the responsibilities and rights of those who emit more than the sustainable level of $\mathrm{CO}^{2}$ and of those who emit less than the sustainable level. To be in accord with the EC-ideal, respondents should agree that 
Paper to be presented at SWEPSA (Swedish Political Science Association), Umeå 27-28/10 2011.

those who presently emit too much have an obligation to decrease their emissions to the sustainable level, but also that those who today emit less than the sustainable level have a right to increase their emissions up to that level.

\section{Data and statistical descriptions}

The empirical study is based on a self-administered mail-questionnaire to 3000 Swedish inhabitants in an age between 18 and 80 years. The fieldwork was conducted during approximately two months from the end of April to the end of June in 2009. The overall response rate was 36 percent, which yielded a total of 1057 completed questionnaires.

Because of the rather moderate response rate, several comparisons have been made with an annual survey carried out by the SOM-institute at the University of Gothenburg, which has an overall high response rate (close to $60 \%$ in 2008) and a reputation for good quality fieldwork and representative samples.

The intention with these comparisons was to examine if the response rate has severely affected the representativeness of our respondents or not. However, the general impression is that the correspondence when it comes to aggregate distributions of both a set of general political and attitudinal variables and a set of socio-economic variables is striking. The most important deviation of our respondents probably is that young people are under-represented and older people over-represented among the respondents. However, this pattern is similar also in surveys with much higher response rates such at the SOM surveys. Our conclusion from these comparisons is that the dataset we use is fairly accurate and representative of the Swedish public despite the moderate response rate.

The central outcome variable in this study is the extent of individual voluntary proenvironmental behaviour. The measure of pro-environmental behaviour (PEB) we use is based on stated behaviour concerning twelve different kinds of pro-environmental behaviours such as trying to save household electricity, buying ecologically labelled food, choosing not to use a car for certain trips and recycling household waste. The respondents are asked to report how often they perform various pro-environmental behaviours on a five-point scale running from "never" to "very often". Since we rely on self-reported behaviour/stated behaviour, we need to 
Paper to be presented at SWEPSA (Swedish Political Science Association), Umeå 27-28/10 2011.

interpret the results with some caution. This kind of measure is prone to wishful thinking and the data may be affected by social desirability bias. However, we are not alone in this. There is indeed a large literature relying on exactly this kind of measurement of PEB within the social sciences. It is also important to note that we do not focus on the level of pro-environmental behaviour among the population; instead our interest remains with group differences and with the correlates of pro-environmental behaviour. Primarily we use a pro-environmental behaviour index constructed by averaging the responses to the twelve PEB items.

A central control variable, typically assumed to affect both attitudes and PEB, is peoples' degree of general environmental concern (Ingelhart 1995), which we measure by asking respondents how worrying for the future they find a large set of different issues. Based on this battery, we construct an index of environmental concern by computing the average of three items concerning climate changes, environmental deterioration and a degraded marine environment.

\section{Results}

Before approaching the main objective of the article, that is, the connection between ecological citizenship ideals and pro-environmental behaviour, let us begin by exploring our first, descriptive, question; to what extent do ecological citizens, holding EC-ideals, exist among the general public? More specifically, this question concerns the degree to which the four above identified and operationalized EC-ideals are being established among the Swedish public? Due to the theoretical complexity of EC, and thus also the operationalization of the same, this section is rather comprehensive.

Most of our empirical indicators of Ecological Citizenship are based on seven point agreedisagree scales from "do not agree at all" (1) to "agree completely" (7) where respondents give their views on various statements that are selected as indicators of each of the four ecological citizenship ideals. However, in a few cases it has been necessary to use other question formats or response scales, primarily to ensure high validity of the data and make sure that we use comprehensible and realistic questions and response. This complicates our analysis at times, and call for certain adjustments in order to make responses to these questions comparable to 
Paper to be presented at SWEPSA (Swedish Political Science Association), Umeå 27-28/10 2011.

our standard seven point scales. For this initial descriptive research question, we mainly rely on means, and the share of respondents whose means fall above or below a mean score of 5.5. Those who reach a mean of at least 5.5 on our scales from 1 to 7 we, rather arbitrarily ${ }^{7}$, consider as coming fairly close to meeting the criteria of being an Ecological Citizen, at least in their minds and thoughts.

\section{Social justice}

The first EC-ideal, the primacy of social justice, is measured through three components: (i) a general sense of fairness; (ii) awareness of ecological footprints; and (iii) other-regarding motives for pro-environmental behaviour. Evaluating the first two components are rather straightforward, as these rely exclusively on items taking the form of seven point agreedisagree statements (see appendix A for a full item wording). The two statements designed to capture a general sense of fairness are normative in nature and pertain to the issue of limited or scarce resources. Taken together, they result in a component-mean of 5.17. The second component, awareness of ecological footprints, is measured using four statements that are strictly descriptive to their nature and concern the respondents' views on the consequences of private consumption. These give a mean for the component of 4.73 .

Lastly, to measure the extent to which the respondents hold other-regarding reasons for behaving pro-environmentally, this component needs to be operationalized through a specific case so as to avoid respondents first by them selves having to determine what constitutes a PEB. We choose to do so here by focusing private ecological consumption and asking the respondents to rate a number of possible reasons for buying eco-labeled products. Six different kinds of motivations were provided, of which three are clearly other-regarding and three concern other kinds of potential beneficial effects of buying eco-labelled goods. However, since

\footnotetext{
${ }^{7}$ Even if the theoretical literature on EC is rather comprehensive (and still growing), hitherto endeavours do not enable us to derive a more exact span within which the responses should be considered "enough" EC, or not. Thus, we here adopt what we consider to be a rather strict definition (5.5/7), compared to how intervals use to be categorised in public opinion research (typically 5/7). Further, due to the arbitrary character of all such criteria, we cannot estimate an absolute level of ecological citizens. Rather, the main interest lies in which of the four core components are more or less fulfilled among the public.
} 
everybody does not buy eco-labeled products at all, respondents also had the opportunity to answer that they "never buy eco-labeled products". This alternative was chosen by 16 percent of our sample, for which we thus have no observations on these three items. ${ }^{8}$ For the remaining 84 percent, the average rating of the three other regarding reasons is 5.34 .

Taken together, the first EC component, Social justice, is measured via nine indicators. When including those who respond to a majority of these questions, this results in 1022 responses, with a mean value of 5.0 on a scale from 1 to 7 . We can thus conclude that the average respondent tends to agree with this EC-ideal slightly more often than they disagree. The share of our sample achieving a score of 5.5 or above on the social justice component of ecological citizenship, amounts to 32.5 percent. The reliability coefficient (Cronbach's alpha) of this index is .77 which is considered reasonably high enough to generate indices.

\section{Dismantling the distinction between public and private.}

Our operationalization of the second EC-ideal is somewhat simpler. It is based on five sevenpoint agree/disagree statement and is not broken down into separate components. The questions are designed as to tap the respondents perceptions on political boundaries, by asking them to indicate the extent to which they agree that politicians and public authorities should be allowed to interfere with the behaviour of ordinary people, as well as whether certain potentially environmental damaging behaviours should be regarded as a private matter or not.

The average of this index is 4.3 and the reliability coefficient is .72 . The share of respondents at or above 5.5 only amounts to 17 percent in this case. Thus, substantially fewer people fulfil the EC criteria when it comes to dismantling the public-private distinction than concerning social justice.

\footnotetext{
${ }^{8}$ To the extent that they have answered all other questions on the Social Justice component they might still be included in the subsequent analysis since we generally demand that people have answered more than half of the items to be included in a certain index.
} 


\section{Unbounded responsibilities}

We measure the extent to which our respondents agree to the EC-ideal of unbounded responsibilities through three components: (i) a temporal extension of justice; (ii) a spatial extension of justice; and (iii) a large scope of obligations. The first component, extension of justice across generations, is measured via a single question where people are asked to choose to what extent the interests of people living today and the interests of future generations should be taken into account when we plan our resource use. The spatial extension of justice, on the other hand, is measured via two items concerning justice in relation to how consumption and lifestyle-choices affect people living in other countries. Lastly, we capture views on a large scope of obligation through two items concerning whether people see it as their obligation to consider the consequences for other people and future generations, in their daily behavioural decisions. Thus, we have in total five items measuring unbounded responsibility.

For the single item measuring the first component, temporal extension of justice, answers are placed on an eleven-point scale that has to be transformed to the same scale as the others items. This is done via a linear transformation, which in the end yields a mean value of 4.8 on the new transformed scale running from 1 to 7 . The second aspect, spatial extension of justice, includes two items and has a mean score of 5.0. The last aspect of unbounded responsibilities is the idea of large scope of obligations, which is also measured via two seven-point items, the mean of which amounts to 5.3. Taken together, an index for the five items making up the ECideal of unbounded responsibilities provides an average of 5.1 and a reliability coefficient of .75. Finally, the share of respondents with an average of 5.5 or higher on the unbounded responsibilities index amounts to 36 percent.

\section{Non-reciprocal responsibility}

Lastly, our attempt at measuring the non-reciprocal responsibility ideal in ecological citizenship-theory includes only two items, asking about the obligation to decrease one's CO2 emissions if being too high and the subsequent right to increase one's emissions if falling below 
a sustainable level, but is never the less rather demanding. In fact, as it turns out, perhaps too demanding. Firstly, we felt that we had to include a "no opinion" option for these questions, since they are indeed harder to answer than some of the others. About 20 percent of our sample has chosen this option for each of the two questions. Secondly, and contrary to the ideas of ecological citizenship theory, we actually find that the two items correlate negatively. This means that, among people in general, those who agree that high emitters have an obligation to decrease their emission are less prone than others to also agree that low emitters have a right to increase their emissions up to a globally sustainable level. Although this correlation is fairly weak, it is statistically significant ( $r=-.11, p=.003, n=743$ ). Indeed, the problem seems to be that an obligation to decrease emissions (mean=5.3) seems more logical to people than a right to emit more (mean=2.4) - even if the present level of the emissions is assumed to be very low.

However, since there are at least some people - approximately ten percent - who agree more than they disagree ( 5 or above on a 7 point scale) on both these questions simultaneously (in accordance with the idea of ecological citizenship), we still chose to use these two questions as intended in accordance with the theoretical model. The mean of the two items becomes as low as 3.8 due to the unpopularity of the "right to increase emissions"-item. Since they are negatively correlated, no scale reliability coefficient can be computed. Using the same criteria as for the other EC-ideals, it turns out that about 12 percent of the respondents score 5.5 or above. Although we have chosen to include these two questions in our general ecological citizenship index, we, in parallel, conduct our analyses without the non-reciprocal responsibility component and this since our finding of a negative correlation certainly cast doubt on the empirical relevance of this component.

To get a more complete overview of the number of respondents who can be characterised as ecological citizens, we finally also construct an overarching ecological citizenship index consisting of all the 21 items presented above. This scale receives a mean of 4.7 and a reliability coefficient of .86. When doing so, it turns out that in total, 21 percent of our sample place themselves at 5.5 or above on this index running from 1 to 7. 
Paper to be presented at SWEPSA (Swedish Political Science Association), Umeå 27-28/10 2011.

Tabell 1 Endorsement of ecological citizenship and its four core aspects

\begin{tabular}{lcccc} 
Component & Percent $>=5.5$ & Mean & Nritems & $\begin{array}{c}\text { Cronbach's } \\
\text { Alpha }\end{array}$ \\
\hline Social justice & 33 & 5.0 & 9 & .77 \\
$\begin{array}{l}\text { imantling public-private distinction } \\
\text { Unbounded responsibility }\end{array}$ & 17 & 4.3 & 5 & .72 \\
Non-reciprocal responsibility & 36 & 5.1 & 5 & .75 \\
Overall EC-index & 12 & 3.8 & 2 & -9 \\
& 21 & 4.7 & 21 & .86 \\
\hline
\end{tabular}

As seen in table 1, in general there is a rather large share of the respondents who fulfils the requirements of ecological citizenship that we have put forth. However, before evaluating these findings, two things should be recalled. Firstly, a noticeably smaller share of people accepts the idea of dismantling the public-private distinction. Secondly, the idea of nonreciprocal responsibilities does not find much empirical support among the Swedish public, although a marginal share of the respondents appear to comply with this view too. Especially, we have seen above that the idea of granting low emitters the right to increase their emissions of carbon dioxide, lack any widespread support.

Let us now move on and attend our second question, namely whether ecological citizenship ideals contribute to pro-environmental behaviour (PEB). Recall that our dependent variable, pro-environmental behaviour, is constituted by an index composed of twelve different activities (e.g., save household electricity, buying ecologically labelled food, choosing not to use a car). To find out what effect EC has on PEB, we test three different models. In the first model, we analyse the EC index alone. In the second model, we analyse the effect of EC with control for environmental concern, as the latter factor has previously been identified as one of the most important drivers for pro-environmental behaviours and attitudes. In the third and most comprehensive model, we now also add several other standard control variables, for example

\footnotetext{
${ }^{9}$ As noted above, the two items upon which this component is based, in fact correlate weakly negatively ( $\left.r=-.11\right)$.
} 
Paper to be presented at SWEPSA (Swedish Political Science Association), Umeå 27-28/10 2011.

socio-economic and political variables. If any significant effects remain from EC when controlling for all these other factors, we cannot reject the importance of ecological citizenship for individual voluntary pro-environmental behaviour. The results from these tests are accounted for in table 2 .

Beginning with model 1 , we see a fairly strong effect of ecological citizenship ideals in themselves (.44) and the effect is most significant $(p<0.01)$. This result surely warrants us to conduct further analyses, and as mentioned above, we now include a measure of general environmental concern in model 2 as a main control variable. This is to see if ecological citizenship has any direct effect in it self - on top of environmental concern. We find that a rather strong (.33) and statistically significant $(p<0.01)$ effect of EC persists. In addition, we observe a modest increase in the model fit (adjusted $R^{2}=.222$ ). This means that by combining EC and environmental concern, we manage to explain slightly more of what affects PEB in total. In model 3, we continue our critical testing by including a wide set of socio-economic and other predictors often used in previous studies concerning pro-environmental behaviour (cf. Guagnano et al, 1995; Stern, 1993). Although the effect of EC diminishes from (.33) to (.23) between model 2 and model 3, when we introduce this comprehensive set of control variables, a clear effect of EC nevertheless remains. As we see, when introducing our broader set of control variables, the importance of environmental concern also decreases slightly. What about the overall explanatory power of our third and most ambitious model? In the bottom of table 2, we find that the adjusted $R^{2}$ increases from (.222) to (.283) when bringing in a comprehensive set of control variables in the model.

\section{Table 2 The impact of Ecological Citizenship ideals on pro-environmental behaviour}

\begin{tabular}{lrrr} 
& Model 1 & Model 2 & Model 3 \\
\hline EC index & & & \\
& $0.44 * * *$ & $0.33^{* * *}$ & $0.23^{* * *}$ \\
& $(0.000)$ & $(0.000)$ & $(0.000)$ \\
Environmental concern & & & \\
& & $0.20^{* * *}$ & $0.18^{* * *}$ \\
female & & $(0.000)$ & $(0.000)$ \\
& & & $0.16^{* * *}$ \\
& & & $(0.000)$
\end{tabular}


Paper to be presented at SWEPSA (Swedish Political Science Association), Umeå 27-28/10 2011.

age

Interest in politics

$0.10 * * *$

Subjective left-right position

Subjective personal retrospective economic

$-0.07 * *$

evaluations

High education

$0.07 * *$

Living in bigger city

Employed

Subjective class

worker

farmer

Comment: Standardized beta coefficients; $p$-values in parentheses.

${ }^{*} p<0.10,{ }^{*} p<0.05,{ }^{* *} p<0.01$. Dependent variable: Pro-environmental behaviour index.

When summing up, we note that the results rather clearly demonstrate that environmental political theorists proposing an expanded ecological citizenship as a viable route towards a deepened public PEB and, thus, a more sustainable society might be on the right track.. At least the way we have operationalized EC, our results suggest that individuals who think along the lines of ecological citizenship are, compared to average people, more likely to behave in an environmentally friendly way in their ordinary lives, and this in addition to other potent explanatory factors of pro-environmental behaviour. 
Paper to be presented at SWEPSA (Swedish Political Science Association), Umeå 27-28/10 2011.

What remains to investigate now is a more in-depth analysis of the four EC components and their relative impact on PEB. This brings us to our third and last question, namely which aspects of ecological citizenship theory are most important for pro-environmental behaviour? Our approach is similar to the one we adopted when answering question two. First, we construct a model where we separate the four EC components and investigate each component's effect on PBE when controlling for the other three. In the second model, we bring in environmental concern as an independent control variable and we can then see each component's effect on PBE on top of environmental concern. Finally, in our third model, we also bring in the long list of socio-economic and other control variables. The results of these exercises are presented in table 3.

When looking at model 1 in table 3, it is clear that all four components of EC theory are not equally important in their implications for voluntary individual pro-environmental behavior. Both sense of social justice and dismantling the public-private distinction have a significant effect, and they are quite noticeable (.26 and .22). The effect of unbounded responsibility is, however, non-existent and insignificant and the effect of non-reciprocal responsibility is only marginal $(.05)$ and barely significant $(p<0.10)$. If we move on to model 2 , controlling for environmental concern, a similar pattern is displayed: the effects of sense of social justice and dismantling the public-private distinction are continuously rather strong (though somewhat weaker than in model 1$)$ and highly significant $(p<0.01)$. It is also worth noticing that - as was also the case in table 2 - by bringing in environmental concern into the model, the model fit increases somewhat too (adjusted $R^{2}$ goes from .187 to .224 ).

\section{Table 3 Aspects of Ecological Citizenship and pro-environmental behaviour}

\begin{tabular}{lrrr} 
& Model 1 & \multicolumn{1}{c}{ Model 2 } & Model 3 \\
\hline EC: social justice & $0.26^{* * *}$ & $0.20^{* * *}$ & $0.14^{* * *}$ \\
& $(0.000)$ & $(0.000)$ & $(0.004)$ \\
& & & \\
EC: private-public & $0.22^{* * *}$ & $0.18^{* * *}$ & $0.14^{* * *}$ \\
& $(0.000)$ & $(0.000)$ & $(0.000)$ \\
& & & \\
EC: unbounded responsibility & 0.01 & -0.04 & $-0.08^{*}$ \\
& $(0.797)$ & $(0.400)$ & $(0.071)$
\end{tabular}


Paper to be presented at SWEPSA (Swedish Political Science Association), Umeå 27-28/10 2011.

EC: non-reciprocal responsibilities

Environmental concern

female

age

Interest in politics

Subjective left-right position

Subjective personal retrospective economic evaluations

High education

Living in bigger city

Employed

Subjective class

worker

$$
0.05^{*}
$$

$0.23 * * *$

(0.000)

$0.18 * * *$

(0.000)

$0.21 * * *$

(0.000)

0.05

(0.143)

$0.08^{* *}$

(0.014)

$-0.12 * * *$

(0.001)

$-0.05$

(0.135)

$0.07^{*}$

(0.071)

$0.11 * * *$

(0.001)

$-0.06 *$

(0.077)

$-0.02$

(0.565)

farmer

Self-employed

0.01

(0.869)

adj. $R^{2}$

0.187

803

0.224

0.301

703

Comment: Standardized beta coefficients; $p$-values in parentheses.

${ }^{*} p<0.10,{ }^{* *} p<0.05,{ }^{* * *} p<0.01$. Dependent variable: Pro-environmental behaviour index.

What about model 3, i.e., when we also add the comprehensive set of control variables? Well, as can be seen from table 3 , this affects our results quite distinctly. First of all, as expected from previous exercises in the paper (read, table 2), the effect of sense of social justice and 
dismantling the public-private distinction decreases further, although they are still noteworthy (.14 in both cases) and remain significant on the 99\%-level. Interestingly enough, unbounded responsibility now has a certain effect (-.08), although it is only significant on the $90 \%$-level and should thus probably be disregarded. It should also be noted that the effect is negative. In addition, we also find that when bringing in the comprehensive set of control variables, we, for the first time, get a significant effect $(p<.001)$ of non-reciprocal responsibility, although it is weaker than for sense of social justice and dismantling the public-private distinction. Finally we have the issue of model fit, which increases by more than $20 \%$ when bringing in the full set of control variables; from $\left(R^{2} .224\right)$ in model 2 to $\left(R^{2} .301\right)$ in model 3 . This means that many of the control variables that we add to our model contribute with additional explanatory value to our model - in addition to the various EC components and general environmental concern. 
Paper to be presented at SWEPSA (Swedish Political Science Association), Umeå 27-28/10 2011.

\section{Concluding remarks}

In this paper, we set out with the aim to examine the relevance of the theory of ecological citizenship (EC) for explaining pro-environmental behavior. In order to do so, we make use of unique survey data from a mail questionnaire sent out to a random sample of the Swedish population in 2009, specifically designed to scrutinize the strength and importance of EC-ideals for driving pro-environmental behaviour on the individual level. Since EC-theory primarily have been developed by environmentally oriented political theorists, its arguments build on theoretical assumptions and elaborations, rather than empirical findings. Yet, EC-theory nevertheless makes a range of empirical claims regarding what factors serve as drivers behind pro-environmental behavior (PEB). The way we interpret the most elaborated forms of EC theory, four broader EC-ideals can be identified: social justice; the dismantling of the publicprivate distinction; unbounded responsibilities; and non-reciprocal responsibility. These ideals reflect values, attitudes, perceptions and norms all assumed to affect PEB in a positive way.

To fulfill our aim, three overarching questions were asked. First, do ecological citizens exist at all? This descriptive question required rather comprehensive elaborations to be able to answer with any satisfaction. We found that the two components that most people agree with are social justice and unbounded responsibilities. Dismantling the public-private distinction was supported by fewer people and non-reciprocal responsibility by even fewer. Finally, we constructed an overall EC index constituted by our four EC-ideals and we could then conclude that, according to our established criteria, about one out of five Swedes can be considered ecological citizens. Thus, the answer to the first question is unambiguous: yes, there are ecological citizens out there.

Our second question dealt with the issue whether ecological citizenship ideals contribute to pro-environmental behavior. We investigated this by considering if the EC index has an independent effect on PBE, which it turned out to have. Most of the independent effect remains also when exposing the index for critical tests, including a rather comprehensive set of control variables consisting of various socio-economic and other predictors. At least the way we have made EC operationalized, our results thus suggest that - compared to average people individuals who think along the lines of ecological citizenship are more likely to behave in an 
environmentally friendly way in their ordinary lives, and this, more importantly, in addition to other potent explanatory factors of pro-environmental behaviour.

Thirdly, we also divided EC into the four core components to see which aspects of ecological citizenship theory are most important for pro-environmental behaviour. It turned out that sense of social justice and dismantling the public-private distinction are the two components whose effects remain stable, significant and most noticeable, despite the comprehensive set of control variables we add to our model. The other two components, however, display a different pattern. The effect of unbounded responsibility remains non-existent until we add our most broad set of control variables, after which we received a barely significant and negative effect (though it was rather weak). Regarding non-reciprocal responsibility, we could notice a more or less insignificantly and rather weak effect until the full set of control variables were introduced. Having done that, a significant effected was again noticed. Both the latter results may indicate, either that these two aspects are not as behaviorally consequential as the others, or that they are not as distinct from other factors as has been argued, and thus need to be further theorized. Of course, we must also consider the possibility that we have not succeeded well enough in operationalizing these two aspects distinctly enough from other parts of EC theory.

To conclude, this paper has demonstrated that Ecological Citizenship ideals, among people in Sweden, are clearly linked to voluntary pro-environmental behaviour. This way of construing citizens' rights and obligations and the limits of their responsibilities, does indeed seem to add some explanatory power in addition to general environmental concern and a large number of standard control variables. In particular an embracement of basic egalitarian ideas of social justice and a dismissal of the idea of a truly private sphere of behaviour seem important for advancing individual voluntary pro-environmental behaviour among citizens. 
Paper to be presented at SWEPSA (Swedish Political Science Association), Umeå 27-28/10 2011.

\section{References}

ACHTERBERG, W. (1993). Can Liberal Democracy Survive the Environmental Crisis? Sustainability, Liberal Neutrality and Overlapping Consensus. In A. DOBSON and P. LUCARDIE (eds.) The Politics of Nature: Explorations in Green Political Theory, pp. 81-104 (London: Routledge).

BARRY, J. (1999). Rethinking Green Politics (London: Sage Publications).

BARRY, J. and M. WISSENBURG (eds.) (2001). Sustaining Liberal Democracy. Ecological Challenges and Opportunities (New York: Palgrave).

BELL, D. (2005). Liberal Environmental Citizenship. Environmental Politics, 14(2): 179-194

BERGLUND, C. and S. MATTI (2006). Citizen and Consumer: The Dual Roles of Individuals in Environmental Policy. Environmental Politics, 15(4): 550-71.

CARTER, N. and M. HUBY (2005). Ecological Citizenship and Ethicallnvestment.Environmental Politics, 14(2): 255272.

CHRISTOFF, P. (1996). Ecological Citizens and Ecologically Guided Democracy. In B.DOHERTY and M. DE GEUS (eds.) Democracy \& Green Political Thought.Sustainability, Rights and Citizenship, pp. 151-169 (London: Routledge).

COHEN, M. J. (2005). Sustainable consumption in national context: an introduction to the special issue. Sustainability: Science, Practice and Policy, 1(1): 22-28.

CONCA, K., T. PRINCEN AND M. MANIATES (2001). Confronting Consumption. Global Environmental Politics, 1(3): 1-10.

CONNELLY, J. and G. SMITH (2003). Politics and the environment: from theory to practice (2nd Ed.) (London: Routledge).

CONVERSE, P. (1964). The Nature of Belief Systems in Mass Publics. In D. Apter (ed.) Ideology and Discontent, pp. 206-261 (New York, NY: Free Press).

DOBSON, A. (1995). Green political thought (London: Routledge).

DOBSON, A. (1996). Democratizing Green Theory: Preconditions and Principles. In B.DOHERTY and M. DE GEUS (eds.) Democracy \& Green Political Thought. Sustainability, Rights and Citizenship, pp. 132-148 (London: Routledge).

DOBSON, A. (2003). Citizenship and the environment (Oxford: Oxford University Press).

DOBSON, A. (2007). Environmental citizenship: Towards sustainable development. Sustainable Develoment, 15(5): 276-285.

DOBSON, A. and R. ECKERSLEY (eds.) (2006). Political Theory and the Ecological Challenge (Cambridge: Cambridge University Press).

DOBSON, A. and VALENCIA SAIZ, A. (eds.) (2007). Citizenship, Environment, Economy (London: Routledge).

DOHERTY, B. and M. DE GEUS (1996). Introduction. In B. DOHERTY and M. DE GEUS (eds.) Democracy \& Green Political Thought. Sustainability, Rights and Citizenship, pp. 1-15 (London: Routledge). 
Paper to be presented at SWEPSA (Swedish Political Science Association), Umeå 27-28/10 2011.

DRYZEK, J. S. (2005). The Politics of the Earth (2nd edition) (Oxford: Oxford University Press).

ECKERSLEY, R. (1992) Environmentalism and Political Theory: Towards an Ecocentric Approach (London: UCL Press).

ECKERSLEY, R. (1995). Liberal Democracy and the Right of Nature: The Struggle for Inclusion. Environmental Politics, 4(4):169-198.

ECKERSLEY, R. (1996). Greening Liberal Democracy: The Rights Discourse Revisited. In B. Doherty and M. de Geus (eds.) Democracy \& Green Political Thought. Sustainability, Rights and Citizenship, pp. 212-236 (London: Routledge).

FELDMAN, S. (1988). Structure and Consistency in Public Opinion: the Role of Core Beliefs and Values. American Journal of Political Science, 32(2): 416-440.

GOODIN, R. E. (1992). Green political theory (Cambridge: Polity Press).

GUAGNANO, G. A., P. C. STERN and T. DIETZ (1995). Influences on attitude-behaviour relationships: A natural experiment with curbside recycling. Environment and Behaviour, 27: 699-718.

HAILWOOD, S. (2004). How to be a green liberal. Nature, Value and Liberal Philosophy (Montreal: McGill-Queen's University Press)

HOBSON, K. (2002). Competing Discourses of Sustainable Consumption: Does the 'Rationalisation of Lifestyles' Make Sense? Environmental Politics, 11(2): 95-120.

HOBSON, K. (2004a). Sustainable Consumption in the United Kingdom: The "Responsible" Consumer at "Arm's Length". Journal of Environment \& Development, 13(2):121-139.

INGELHART, R. (1995) Public Support for Environmental Protection: Objective Problems and Subjective Values in 43 Societies. Political Science and Politics, Vol. 28, No. 1, (Mar., 1995), pp. 57-72

JACOBS, L- R., C. J. GLYNN, S. HERBST, G. O'KEEFE and R. Y. SHAPIRO (1999). Public Opinion and Policymaking. In C. J. GLYNN, S. HERBST, G. O'KEEFE AND R. Y. SHAPIRO, Public Opinion, pp. 299-340 (Boulder, CO: Westview Press).

JAGERS, S. C. and S. MATTI (2009). Ecological citizens: Identifying values and beliefs that support individual environmental responsibility among Swedes (Under review for Political Psychology).

JAGERS, S.C. and H. HAMMAR (2009). Environmental taxation for good and for bad: the efficiency and legitimacy of Sweden's carbon tax. Environmental Politics, 18(2): 218-237.

JAGERS, S.C. (2009) “In search of the Ecological Citizen” Environmental Politics 18(1) p 18-36

JELIN, E. (2000). Towards a Global Environmental Citizenship. Citizenship studies, 4(1): 47-63.

LUNDMARK, C (2003). The Politics of Recycling - A Liberal Democratic Dilemma. European Environment, 13, 120131.

MANIATES, M. F. (2001). Individualization: Plant a Tree, Buy a Bike, Save the World. Global Environmental Politics, 1(3): 31-52.

MATTI, S. 2009: Exploring public policy legitimacy: a study of belief-syste, correspondence in Swedish environmental policy. Doctoral thesis, Luleå University of Technology

MICHELETTI, M. (2003). Political Virtue and Shopping: Individuals, Consumerism, and Collective Action (New York: 
Paper to be presented at SWEPSA (Swedish Political Science Association), Umeå 27-28/10 2011.

Palgrave Macmillan).

NORDLUND, A. AND J. GARVILL (2002). Value Structures Behind Proenvironmental Behaviour. Environment and Behaviour, 34(6): 740-756.

PROHOVNIK, R. (1998). Public and Private Citizenship. From Gender Invisibility to Feminist Inclusiveness. Feminist Review, (60): 84-104.

ROKEACH, M. (1973). The Nature of Human Values (New York: Free Press).

SAGOFF, M. (1988). The Economy of the Earth (Cambridge: Cambridge University Press).

SAWARD, M. (1993). Green Democracy. In A. DOBSON and P. LUCARDIE (eds.) The Politics of Nature: Explorations in Green Political Theory, pp. 63-80 (London: Routledge).

SEYFANG, G. (2005). Shopping for Sustainability: Can Sustainable Consumption Promote Ecological Citizenship? Environmental Politics, 14(2): 290-306.

SEYFANG, G. (2006). Ecological citizenship and sustainable consumption: Examining local organic food networks. Journal of Rural Studies, 22: 383-395.

STEG, L., L. DREIJERINK and W. ABRAHAMSE (2005). Factors influencing the acceptability of energy policies: A test of VBN theory. Journal of Environmental Psychology, 25: 415-425.

STERN, P. C., T. DIETZ and L. KALOF (1993). Value orientations, gender, and environmental concern. Environment and Behavior, 25: 322-348.

STERN, P. C., T. DIETZ, L. KALOF and G. A. GUAGNANO (1995). Values, Beliefs, and Proenvironmental Action: Attitude Formation Toward Emergent Attitude Objects. Journal of Applied Social Psychology, 25(18): 16111636.

STERN, P.C. (2000). Toward a coherent theory of environmentally significant behaviour. Journal of Social Issues, 56: 407-424.

STERNER, T. (2003) Policy Instruments for Environmental and Natural Resource Management Thomas Sterner RFF Press 2003, Washington DC

VAN STEENBERGEN, B. (1994). The Condition of Citizenship: an Introduction. In B. Van Steenbergen (ed.) The Condition of Citizenship, pp. 1-9 (London: Sage Publications).

WACKERNAGEL, M. and W. E. REES (1996). Our Ecological Footprint: Reducing Human Impact on the Earth (Philadelphia, PA: New Society Publishers).

WOLF, J., 2007. The ecological citizen and climate change. Paper presented to the workshop 'Democracy on the day after tomorrow', ECPR (European Consortium for Political Research) Joint Sessions, Helsinki

ZALLER, J. R. (1992). The nature and origins of mass opinion (New York: CambridgeUniversity Press). 


\section{Appendix 1. List of Indicators of Ecological Citizenship (to be completed later)}

This list is a summary of question wording and response categories. Some items had a separate introduction to the question. The full questionnaire can be retrieved from the authors.

\section{Social Justice/sense of fairness.}

To what extent do you agree with the following statements:

( 1 do not agree at all -7 agree completely)

General sense of fairness

Each person should not consume more of the world's resources than what allows all people to have their basic needs met?

The resources should be distributed equally among all people of the world?

\section{Awareness of ecological footprints}

Many of the products consumed in Sweden affect the environment in other countries negatively?

When we consume products in Sweden, we often consume resources from other countries?

The concern that the Swedish consumption harms the environment elsewhere is exaggerated?

(reversed)

A great deal of the Swedish hazardous waste eventually ends up in poor countries?

Reasons for pro-environmental behaviour are other-regarding

How important are the following reasons when you buy eco-labelled goods:

(1 not at all important - 7 very important)

Ecological products have less environmental impact?

Ecological products are better for the individuals who produce the products?

It affects the development of society in an environmentally friendly direction?

\section{Dismantling the distinction between public and private.}

To what extent do you agree with the following statements:

( 1 do not agree at all -7 agree completely)

Politicians and authorities should not concern themselves with whether or not people act environmentally

friendly? (reversed)

It's good that politicians and authorities try to make people act more environmentally friendly?

If I choose to drive a car, it's my private business? (reversed)

If I choose to eat meat, it's my private business? (reversed)

\section{Unbounded responsibility.}

To what extent do you agree with the following statements:

(1 do not agree at all - 7 agree completely)(

It is unfair that the Swedish consumption consumes natural resources in other countries?

It is unfair that the Swedish lifestyle damages the environment for people in other countries? 
Paper to be presented at SWEPSA (Swedish Political Science Association), Umeå 27-28/10 2011.

When I consume products in Sweden I have an obvious obligation to consider the consequences of my consumption for people in the countries where the products were produced?

When I consume products in Sweden I have an obvious obligation to consider the consequences of my consumption for future generations?

\section{Non-reciprocal responsibility.}

To what extent do you agree with the following statements:

(1 do not agree at all -7 agree completely)

Those who emit more than .5 tonnes per year have a responsibility to reduce their emissions to .5 tonnes per year?

Those who emit less than .5 tonnes per year have the right to increase their emissions to .5 tonnes per year 